\title{
The Great Exaptation. Around the fundamental idea of evolutionary psychology
}

\author{
Magdalena Reuter
}

Departament of Epistemology and Cognitive Sciences, Institute of Philosophy, Adam Mickiewicz University, ul. Szamarzewskiego 89C, 60-568 Poznań, Poland e-mail: magda.reuter@gmail.com

\begin{abstract}
The subject of this article is to study the critique of the adaptationist programme in the evolutionary psychology. I focus on the issue how the notions of "spandrel" and "exaptation", first introduced to evolutionary biology by S. J. Gould, R. Lewontin and E. Vrba, were then applied to the field of evolutionary psychology and to more broadly evolution of human cognitive processes. My aim is to show, that these terms are differently applied to various kinds of investigations in the field of the evolution of human mind. I show that not only the orginal definitional issues are problematic but also the application of these terms to evolution of human mind can be confusing. I try to put the main issues in order on that matter and propose the solutions to these confusions. I propose the methodological assumptions that should be accepted to the theory of spandrels and exaptations.
\end{abstract}

Key words: adaptationist programme, cognitive processes, evolution of human mind.

\section{The critique of adaptationist programme in evolutionary biology}

In 1979 Stephen Jay Gould and Richard Lewontin in their most influential article The spandrels of San Marco and the Panglossian paradigm presented the critique of the adaptationist programme, which they called "too optimistic Panglossianism". They indicated that the adaptationist idea, which entirly dominated the evolutionary biology from the $1940 \mathrm{~s}$, is in fact a false attempt to explain the existence and the particular forms of any phenotipic traits as being a result of natural selection solely. In their critique they tried to show that radical adaptationists don't distinguish a currently useful characteristic from the orgin for which it came into being. Moreover, they produce a chain of neat but false adaptationist stories saying that each trait arose on the way of natural selection. These are often false "just so stories".

From the point of view of both authors, evolutionary theory lacks crucial term, which would signify the trait, that is a by-product of the adaptation and that currently can (but not necessarily) enhance fitness. To indicate adaptationist's mistakes the reaserchers presented architectural methaphor. The title "spandrels of San Marco" are the tapering triangular spaces between the archways supporting the domed roof of the famous basilica in Venice. These spaces are necessary architectual by-products of a mounting dome on rounded arches, so they are just a result of architectual constraints. But then an architect took advantage of the triangles and decorated them with frescos of four Ewangelists. The beautiful paintings currently perform aestetic functions, but the spandrels themselves weren't built to be served as painworks. The exact situation is in the architection of biological organisms, as Gould and Lewontin argue. The phenotipic traits not always arise as an adaptations, some of them are the by-products of adaptive characteristics of the organism.

In 1982 Stephen Jay Gould and Elisabeth Vrba in the article Exaptation; a missing term in the science of form in- 
troduced the term "exaptation" to the evolutionary biology. This term came into being to distinguish two meanings of the term "adaptation". The first one is the most common usage of this term and refers to "the trait that was shaped by natural selection to perform the particular function". It emphasizes the origin of the trait. The second meaning refers to the "trait that has currently the influence on survival and reproduction". What is essential here is the current usage of the trait, but not its origin. The term "exaptation" was introduced to underline the current usage of the trait that didn't came into being by natural selection, so that was not the adaptation in the first sense. Here is as Gould explains the necessity of introducing of the new term:

"We do regret the retention of the same word - adaptation - for both a process and the utility arising by the process, but we bow to entrenched convention here. We then fill in the previous gap by coining exaptation for useful structures coopted from other contexts - for such structures are fit (aptus) not by explicit molding for $(a d)$ current use, but as a consequence of (ex) properties built for other reasons" (Gould 1991, p. 47).

Generally, the term "exaptation" defines "features that now enhance fitness, but were not built by natural selection for their current role" (Gould \& Vrba 1982, p. 4). But it seems that these reaserchers use it in their articles in two different meanings. Firstly, as if, it charaterized "features evolved by selection for one purpose are coopted for another" (Gould 1991, p. 53); secondly, as if it described "presently useful characters did not arise as adaptations (...) but owe their origin to side consequences of other features" (Gould 1991, p. 53).

It seems that there are two different kinds of exaptaion and each of them has different origin. However, two different definitions are sometimes confusing. Is exaptation currently a useful feature- that didn't arise as adaptation, but whose function was coopted on the base of orginal adaptation or is it rather a currently useful side effect of adaptation? To cope with this incomprehensible and ambiguous depiction, David Buss et al. proposed to call the first meaning of exaptation co-opted adaptation and the second one co-opted spandrel (Buss et al. 1998). This proposal is useful as it reveals that the exaptation is always currenlty useful trait, whose origin can be of two different kinds - the first one, which is based on an orginal adaptation, and the second one that is based on a spandrel which is the by-product of an adaptation.

In his article written in 1991, Gould also explains why he coined the new term instead of useing the old one, which functions in the evolutionary dictionary - "preadaptation". He argues that this old term covers only the first one of the two styles of cooptation. It seems that it agrees with the exaptation in its first sense (as coopted adaptation). In evolutionary biology "proto-wing", which seems to have evolved on the way of natural selection for ther- moregulation, is often called the "preadaptation" to flight. Gould says it is the exaptation in the first sense. But how about all of the exaptations in the second sense, which didn't evolved by natural selection but are only the byproducts of adaptations that later were coopted to perform function? The researcher says that the new term covers not only the old term "preadaptation" but also "the large domain of nonaptations later coopted for utility" (Gould 1991, p. 48).

The most frequent example in the literature of the first category of exaptation - as co-opted adaptation - are the feathers of birds, that first evolved for thermal regulation, but then were co-opted for flight. The common example of spandrel is the human chin or the human eartips, that didn't evolved for the particular purpose, but currently can perform some functions (for example to wear on them earrings) and thus became an exaptation in the second meaning - as co-opted spandrel.

\section{Definitional and conceptual confusions about the terms "spandrel" and "exaptation"}

\subsection{Definition of "exaptation", "spandrel", "preadaptation", "nonadaptation"}

In my opinion, the semantic constraints of the new terms weren't sharply outlined. First of all, we should consider what in fact is spandrel instead of exaptation. Is it one of the cases of exaptation which covers only the second part of the cooptation, or is it maybe one of the cases that the term "spandrel" covers the term "nonaptation", which is not useful the by-product of the adaptation? The solution to this confusion is important because this term is often used in two different meanings. First, as not useful by-product of adaptation (in this sense it entirely covers the term "nonaptation") and on the other hand, as coopted nonaptation (in this sense it covers the half of the semantic field of the term "exaptation"). I opt for the first of the two definitions, as in the Gould's papers it prevails. We can read there such statements: "Spandrels are architecturally enforced byproducts of primary changes. But spandrels may then be subsequently coopted for highly fruitful use - leading to the result that Gould and Vrba called exaptation" (Gould 1997, p. 10752). In this context Gould often says about "exapted spandrels" (Gould 1991, p. 47). That is why we should rather refer this term to nonaptation that later had been coopted to perform another function. 


\subsection{Biological function vs. Function in a colloquial meaning}

The second confusion is a problem with the term "function" in the proposed definitions. Although it is the main component of the definitions of "exaptation", Gould seems not to use it in a proper way. In some places he admits that "adaptations have functions, but 'function' cannot describe the utility of an exaptation" (Gould 1991, p. 47) and argues that it is better to "designate the utility of the exaptation as an 'effect"' (Gould 1991, p. 48).

Moreover, Gould introduced "a taxonomy of fitness", where he distingushed process, character and usage. The first process is a natural selection, which shapes the character - adaptation - to perform particular biological function. The second process is cooptation based on the adaptation - a character previously shaped by natural selection for a particular function (an adaptation) is coopted for the new useage. This is the first kind of exaptation (as coopted adaptation) and it's usage is not a function but an effect. The third process is cooptation based on the by-product of adaptation (exaptation as coopted spandrel). Its usage is also the effect.

An interesting thing is that both "adaptation" and "exaptation" have in their definitions the term "aptation", thus both in some general sense enhance fitness. "We recognize, of course, that distinction of adaptation from exaptation requires knowledge of historical sequences - and such an evidence is often, if not usually, unavailable. In such cases, we may only know that a structure is currently useful - and we may be unable to identify the source of utility. In such cases, we urge that the neutral term 'aptation' (encompassing both ad- and ex-aptation) should be used in place of the conventional and falsely inclusive 'adaptation"' (Gould 1991, p. 47).

Gould suggested that only adaptation can perform function instead of two kinds of exaptation which are only the effects. So why did he previously use the term "function" in the definition of "exaptation"? And why then he says it's effect that is important in this definition? It seems that he previously used this term in a colloquial meaning. On the other hand, it isn't clear whether behind the term "function" stands the function in a biological sense or not.

To describe what he means by "effect" Gould cited Williams example: "flying fishes fall back into the water by virtue of gravity, and this descent is essential to their continued existence. But weight, as an inevitable property of matter in Newton's world, is an exaptation for falling back, clearly not an adaptation. In ordinary English usage, we would not call falling back a function of weight. We therefore, following Williams, designate the utility of an exaptation as an "effect" (again choosing vemacular English - falling back is an effect of weight)" (Gould 1991, p. 47-48).
But exaptations are not only effects, like in quoted example, but also "culturally useful features" of the brain. Gould notices that large size of the brain is an adaptation, but everything what the brain can do isn't probably strictly shaped by natural selection. "Surely, for something so complex and so replete with latent capacity as the human brain, spandrels must vastly outnumber original reasons, and exaptations of the brain must greatly exceed adaptations by orders of magnitude (...) Surely, the central traits of human culture, and the essences that define our concept of human nature, must arise more often as exaptations than as adaptations" (Gould 1991, p. 58).

To qualify as exaptations culturally useful features as well as effects seem to have biological function. However, as Buss et al. noticed, "it seems implausible that Gould intended to claim that such cultural practices as reading and writing are explainable by biological functions" (Buss et al. 1998, p. 541). From the point of view of these reaserchers novel uses of existing mechanisms are not explained by the biological functions thus they are not exaptations. There should be a sharp distinction between true functional exaptations, such as the feathers of birds co-opted for flight, and novel uses of existing mechanisms that are not explained by biological function (Buss et al. 1998).

\subsection{Volutionary history of the feature vs. current utility}

When evolutionary biologists and psychologists attempt to explain the existence of a particular chatacteristic they refer to the evolutionary history and to the past fitnessenhancing effects that led to the current feature or mechanism in the species. But the definition of exaptation proposed by Gould requires that the feature now enhances fitness and it seems that it isn't important how this feature came into being. As Gould repeatedly outlined, the current utility should be distinguished from its orgin. This issue is problematic for evolutionary biologists as well as for psychologists, as their explanations of current characteristics refer to past selective pressures. As Buss et al noticed, "Obviously, a characteristic cannot be explained by current fitness-enhancing properties that came about after the characteristic already existed.(...) Evolutionary explanation focuses on explaining why a feature exists, not what incidental interactions the feature may be having with the current environment" (Buss et al., 1998, p. 540). For example, when they try to explain the human taste for fatty foods they refer to past selective pressures which led to ensure adequate caloric intake.

Gould explains that it is often not possible to reveal the origin of the trait, thus it is problematic to reveal which characteristic is an adaptation and which an exaptation. "But if we now have available only the modern structure with its mix of primary adaptations and secondarily exa- 
pted spandrels - the usual situation in biology when we do not have a fossil record of actual historical stages leading to a present structure - then how can we identify and allocate the proper statuses? After all, both types of features may now be exquisitely well "crafted" for a current utility - for the exapted spandrel may work just as well, and may be just as crucial to current function of the whole, as the primary adaptation" (Gould 1997, p. 10752).

\subsection{What is the process of co-opting in the cases of human cognitive skills?}

After analizing the problems mentioned above, the next important issue is the question concerning the problem of the process responsible for co-opting an existing structure into the other one that perform a different function. As Buss et al. noticed in the example of birds' feathers, it is a natural selection that coopted the existing structure with the function of thermoregulation into a new modified structure with a new function of flying (Buss et al. 1998). Thus we can conclude that in the cases of exaptations of the first kind - as coopted adaptations - it is the natural selection which is the causal process responsible for cooptation. Nevertheless, there is still a question: what about the second kind of exaptations - coopted spandrels?

More confusing is Gould's explanation of the mechanisms of co-opting in the evolution of human mind. He agrees with the ultra-Darwinian point of view that human brain evolved by natural selection, but he disagrees with the statement that all of the human capacities are adaptations. Because of the complexity of the human brain, most of the human skills are exaptations and in his opinion the term exaptation "becomes a crucial concept for an evolutionary psychology" (Gould 1991).

The processes responsible for co-opting new function of human brain are thus human cognitive capacities, human actions and motivational mechanisms. Consider human capacity for playing the piano. Human hands didn't evolve to play the keyboard because it is recent evolutionary manifest behaviour. To understand this capacity, we have to relate not only to the structure that is used - human hand and the function that is currently performed - clatter in the keyboard, but also to the whole cognitive activity of playing the piano, which may be understood by human motivational mechanisms (like social networking, enhancement of appearance) and human cognitive capacities (like music skills) on other hand, which are responsible for coopting existing mechanisms into the other useage.

This example shows that there are significant differences between biological exaptations based on adaptations, which function was transformed from one to the other by natural selection, and the exaptations which are the result of co-optation based on human psychological processes. Such evolutionary novel human capacities like reading, writing, playing the violin, tennis and chess are presumably too recent to be co-opted by natural selection (Buss et al. 1998, p. 541).

\section{Human cognitive skills and cognitive prosesses as spandrels and exaptations}

Since the time of the first Gould and Lewontin's articles the terms "spandrel" and "exaptation" started to be broadly used in discussions about the evolution of human mind. As Gould suggested most of the human capacities evolved rather as spandrels and exaptations than as adaptations. Some psychologists started to refer to these new categories as they seem to solve the problem of how such evolutionarily recent capacities of human mind could appear on the way of natural selection, which acts on the long periods of time. It is the argument which led reaserchers to consider most of human cognitive skills as the by-products of complexity of human brain.

Evolutionary reaserchers enumerate the list of the features of human mind which are spandrels and exaptations rather than adaptations. The first feature is human ability to create language. Did the language evolve by natural selection to perform a function of communication or is it rather a by-product of the complexity of human brain that later started to enhance fitness? The second view is supported, among others, by Noam Chomsky, Marc Hauser and Tecumseth Fitch: "We consider the possbility that certain specific aspects of the faculty of language are 'spandrels' - by-products of pre-existing constraints rather than end products of a history of natural selection" (Chomsky et al. 2002, p. 1574). Stephen Pinker in his book "The Language Instinct" deal with the Chomky claim that all human language shows evidence of the universal grammar but disagree with him that evolution by natural selection is not able to explain a human language instinct (Pinker 1997).

The second feature of human mind considered in this context is the abitilty to create and perceive music. The evolutionary psychologists think over what adaptive functions does music serve? If we are radical adaptationsts we claim that the ability to create and percive music is an adaptation, and those of our ancestros who possesed and expressed musical skills out-reproduced those who didn't. But as Darwin noted, perceiving and creating music is one of the most amazing capacities of human mind: "As neighter the enjoyment nor the capacity of producing musical notes are faculties of the least use to man in reference to his daily habits of life, they must be ranked amongst the most mysterious with which it is endowed" (Darwin 1874, 2007, p. 475). One possibility to answer the "mystery" is to refer to the concept of spandrel. Music may be the by-product of other human capacities as for example language, which itself is an adaptation. This view 
is supported by Stephen Pinker for whom music is just "auditory cheesecake". He writes that "music is useless. It shows no signs of design for attaining a goal such as long life, granchildren, or accurate perception or prediction of the world. Compared with language, vision, social reasoning, and physical know-how, music could vanish from our species and the rest of our lifestyle would be virtually unchanged" (Pinker 1994). But this standpoint is broadly criticized (Levitin 2006).

Another candidate for spandrel in the field of evolution of human cognitive processes is self-deception. Neil Van Leeuwen criticizes common explanation of this phenomena introduced by Trivers (Trivers 2000) and taken for granted in a evolutionary psychology that the ability to self-deceive was shaped by natural selection to support deciving of the others. He argues that Trivers is wrong, because self-deception occurs often without deceiving others and vice versa - deceiving others have sense only when the deceiver himself is not deceived. Thus, self-deception may be the spandrel of another adaptive traits of human cognitive system such as general inclination to avoid discomfort, human selective attention to evidence and inputs, seeking comfort etc. (Van Leeuwen 2007).

The last example of the career of the term 'spandrel' in evolutionary psychology comes from the field of evolution of human memory. In "The seven sins of memory" Daniel Schacter argues that memory errors are not disadvantages of the cognitive system but rather its virtues. The psychologist aplicates the concepts of 'spandrel' and 'exaptation' to this field. Some of the memory errors, he argues, are adaptations (like transience and persistence) but most of them are rather by-products of the adaptive memory mechanisms. The spandrels are blocking, absent-mindedness, misattribution, suggestibility (Schacter 2001). The autor explains the basic mechanisms of memory (like selective attention, encoding memory schemas, mechanisms of recollecting the emotional memories) that are useful features of our memory system but have constraints that may lead to by-products (spandrels).

The example of currently useful exaptation, that wasn't shaped by natural selection but currently can enhance fitness is the error of bias. Schacter doesn't explicitly explain which kind of exaptation of the Gould's definitions he means, but it seems as if he considered the coopted spandrel. He claims that the positive biases such as believing that we are more consistent than we really are in our relationship choices or our outlook on life might help to improve our self-confidence and thus enhance fitness. On the other side, change biases such as believing that we changed our bad stance or gave up the habit when in fact we didn't or the effects are not so amazing as we think, may motivate us to continue to change and is advantageous to our positive attitude towards ourselves. These may lead

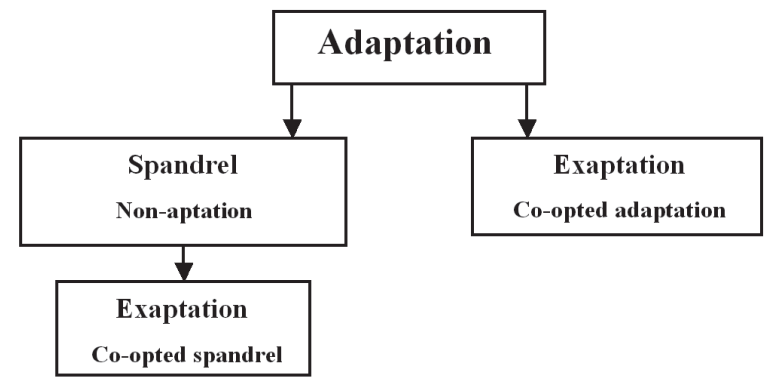

Figure 1. The origin of "exaptation" and "spandrel". Two kinds of exaptation (based on Buss et. al. 1998)

us to overall satisfaction with life and thus fitness is enhancing (Schacter 2001).

The terms 'spandrel' and 'exaptation' are differently apllied to the field of evolutionary psychology. Sometimes they are apllied to show that a specific human ability was not shaped by natural selection - as in the examples with language and music. On the other hand, they are apllied to the field of human cognitive processes as in the example with the process of self-deception. And in the last example, spandrels and exaptations are human memory errors as the effects of memory processes. In my opinion, the practice of application the terms 'spandrel' and 'exaptation' to such diffrent categories as abilities, cognitive processes and effects of cognitive processes - leads to many confusions.

The other important thing is the problem with testing the hypothesis that a cognitive process or its effect is the spandrel or exaptation. There is no way to verify this and this is weakness of Gould's conception. However, instead of the fact that this conception has a lot of problems to solve, in my opinion it is worth being considered and developed in the field of evolutionary psychology.

\section{References}

Buss D. M., 1995, Evolutionary psychology: A new paradigm for psychological science, Psychological Inquiry 6: $1-30$.

Buss D. M., Haselton M. G., Shackelford T. K., Bleske A. L. \& Wakefield J. C., 1998, Adaptations, Exaptations, and Spandrels, American Psychologist 53(5): 533-548.

Chomsky N. et al., 2002, The faculty of language: what is it, who has it, and how did it evolve?, Science 298: 1569-157.

Darwin Ch., 1874; 2007, The Descent of Man, First published in 1874, Republished by Forgotten Books (http:// www.forgottenbooks.org/info/9781605062815). 
Dennett D. C., 1995, Darwin's dangerous idea, Simon \& Schuster, New York.

Gould S. J., 1991, Exaptation: A Crucial Tool for an Evolutionary Psychology, Journal of Social Issues 47(3): 43-65.

Gould S. J., 1997, The exaptive excellence of spandrels as a term and prototype, Proceedings of the National Academy of Sciences 94: 10750-10755.

Gould S. J. \& Lewontin R., 1979, The spandrels of San Marco and the Panglossian paradigm, Proceedings of the Royal Society of London, Series B, 205: 581-598.

Gould S. J. \& Vrba E. S., 1982, Exaptation: A missing term in the science of form, Paleobiology 8(1): 4-15.

Levitin D., 2006, This Is Your Brain on Music: Understanding a Human Obsession, Dutton Adult (Penguin), New York

McKay R. \& Dennett D. C., 2009, The evolution of misbelief, Behavioural and Brain Sciences 32: 493-561.

Pinker S., 1997, How the mind works, W. W. Norton \& Company, New York.
Schacter D. L., 2001, The seven sins of memory: how the mind forgets and remembers, Houghton Mifflin, New York.

Sherry D. F. \& Schacter D. L., 1987, The Evolution of Multiple Memory Systems, Psychological Review 94(4): 439-454.

Trivers R., 2000, The elements of a scientific theory of self-deception, Annals of the New York Academy of Sciences 907: 114-131.

Trivers R. L., 2006, Foreword to Richard Dawkins' The Selfish Gene, [in:] The selfish Gene: 30th anniversary edition (pp. XIX-XX), Oxford University Press Oxford.

Van Leeuwen D. S. N., 2007, The spandrels of self-deception, Philosophical Psychology 20(3): 329-348.

Van Leeuwen D. S. N., 2007, The product of self-deception, Erkenntnis 67: 419-437.

Van Leeuwen D. S. N., 2008, Finite rational self-deceivers, Philos. Stud. 139: 191-208. 